\title{
Quality of Care and Psychological Wellbeing of Differently Abled Children in Embu County Kenya
}

\author{
Henry Kathuri Ndwigah, Stephen Asatsa (PhD) and Elijah N. Macharia (PhD) \\ Department of Psychology, The Catholic University of Eastern Africa
}

\begin{abstract}
The care of children with motor impairments is a global concern. Their psychological wellbeing is a great concern for those living with them. This study aimed at investigating the quality of care given to these children and their psychological wellbeing in Embu County, Kenya. The study adopted crosssectional research design to collect data. A sample size of 80 participants was selected using census method. Data were collected using the Ryff's psychological wellbeing scale, a sociodemographic questionnaire and a self-developed questionnaire for assessment of quality of care given to the differently abled children. The study findings showed that the quality of care given to the differently abled children in the family, residential institutions and educational institutions has weak positive and significant correlation with personal growth domain of the psychological wellbeing scale $(r=0.320, p<0.05 ; r=$ $0.329, p<0.05$; and $r=0.449, p>0.05$ respectively. The results imply that enhancing the quality of care to differently abled children is vital in the psychological health of differently abled children.
\end{abstract}

Key Words: Family Care, Institutional Care, Differently Abled

\section{INTRODUCTION}

$\mathrm{P}$ eople with different impairments are usually received with mixed feelings by different people in the world. They live either in their families or in residential or in educational institutions (Bayat, 2017). Impairments are visual if associated with sight, audio if associated with hearing, cognitive if associated with mental functioning and motor if associated with limited or no use of limbs (Orr, 2015). This study specifically focused on the children with motor impairments, those with limited use of their limbs. UNICEF (2013) gave a report on the state of the world's children with disabilities stating that these children have additional challenges and barriers and generally suffer exclusion in many occasions. This basically would raise psychological issues to these children.

Grant, Ramcharan \& Flynn (2007) did a study in Europe. The title of the study was "Participation and quality of Life of Children with Disabilities Living in Europe". This was to investigate the influence of the environment on the participation and quality of life of disabled children aged 8-12 years. It was conducted in seven EU countries, that is, Denmark, France, Germany, Ireland (North and South), Italy, Sweden and England. It was found that the participation and quality of life of disabled children and adolescents was lower compared to those without disabilities. This was in terms of social support and peer relationships. The participation and quality of life for the children with motor impairment depended on the environment where they lived. This environment which would be at the families of the disabled children or in residential and educational institutions, determined the psychological wellbeing of these children (Bayat, 2017). This was from the care they received in the environment they were found.

A study done in Zimbabwe by Janet and Lazowski in 2012 focused on children with physical impairment. The title was 'The psychological well-being of adolescents with physical disabilities in inclusive community settings'. The findings indicated that the adolescents with disabilities and living in such inclusive communities had high levels of autonomy and choice, purpose in life, positive relations with others and good personal growth and self-acceptance. The study also found that the adolescents with disabilities ended up being rejected and stigmatized across many cultures by some discrediting and dehumanizing statements made about their attributes. This was seen to have impacts on their psychological wellbeing since at times they were also considered as less than fully human thus minimizing the care they received from the care givers (Lazowski, 2012).

In Kenya a survey entitled "Kenya National Survey for Persons with Disabilities" was done and a report written in 2008. The report indicated that the establishment and emergence of many small homes for disabled children in the country would create concern about the care given in these institutions. This was in comparison to the care given in the families. The concern was to establish whether the institutionalized children had any psychological developmental difference from those living in their families. It was found out that $65 \%$ of children with disabilities regarded the environment as major problem in their daily lives as later established by KNCHR (2014). These findings pointed to the fact that the environment where these disabled children live in may have effects to their psychological wellbeing.

The general understanding of psychological wellbeing consists of positive relationships with others, personal mastery, autonomy, a feeling of purpose and meaning of life and personal growth and development (Ryff, 2017). Specifically the psychological wellbeing for children is based on provision of their rights and addressing their developmental transitional issues (Arieh et al, 2007). This means that the care given to the children and their psychological wellbeing involves providing the basic rights 
for the children and addressing their developmental changes as they mature.

The concept of disability has a general meaning of the various types of disabilities. The term "disabled" has been used generally together with words like "physically challenged", "handicapped" and "less fortunate" (Badu, 2016). These terms indicate the motor type of impairment. The motor impairment is characterized by the limited use of limbs due to various causes (Badu, 2016). The reason for the choice of this type of impairment in the study was that it fitted very well with the concept of different abilities. The study used "differently-abled" to imply that these children have their own abilities in their own ways besides their motor limitations. Though the children have motor impairments they have other functional faculties like sight, hearing and intellectual abilities among others. These children lack only the limbs coordination and movements and therefore they are termed as differently-abled.

The concept of care generally refers to the provision of what is necessary for health, wellbeing and protection of a person. This study considered four types of care for the differently-abled children. These were the family care, residential institutional care, educational institutional care and the psychological care. This is because the children with motor impairments live either in the families, residential and educational institutions (Bayat, 2017). They also require psychological care just like any other human being (Kendra, 2019). Family care is provided at home by the parents, siblings and other relatives. Residential institutional care is given in small homes, orphanages and charitable institutions by some designated staffs. Educational institutional care is given at the places where these children undergo formal education. The psychological care is given by the chaplains and the counselors to the children within their reach.

All the children whether disabled or able bodied require family care (Government of Kenya, 2001). This family care entails provision of food, clothing, shelter, care, protection from abuse and general support as they mature (Chernego, 2016). In some families the children with motor impairments are viewed as a source of strength, hope, joy, love and pride (Mulheir, 2012). However in many families these children are neglected and many family members are not willing to expose them due to cultural, parenting or family patterns of secrecy (Kett and Ommeren, 2009).

There are many other families with children with motor impairments who find it challenging to care for them in their families due to various factors. They therefore end up taking them to residential institutions where these children can receive the care that may not be available in their families (Zuurmond et al, 2016). This residential institutional care revolves around feeding, sleeping, moving around, challenging behavior, communication and connecting them with others. In some cases the family members occasionally visit these children while in other cases they don't. Still many charitable organizations and individuals visit these institutions and deliver material things to the children living there. Kendra (2009) says that many of these people who visit these children are more led by pity than respect. This is because with pity the people concentrate on the ordinary needs of these children and fail to recognize their uniqueness and other psychological elements. Though there is provision of the basic needs and some other requirements at residential institutions in Runyenjes Constituency, there are some incidents of continuous withdrawal of differently-abled children from these institutions over the last four years (Gender and Social Services, Embu West Sub-county, 2019). This necessitates the study to find out the amount of care at the residential institutions and the reason for preference by many families to take their differently-abled children out of these residential institutions.

A recent most practical program on inclusion is in the area of education that sees the differently-abled children schooling together with the able bodied children (Arieh et al, 2017). This involves accommodating even the physically challenged children into the system of formal education. The differently-abled children who attend educational institutions come from their families or from their residential institutions. Here they are able to learn how to read, write, communicate, concentrate and develop their personal abilities (Malinda, 2005). Runyenjes Constituency has three schools that were involved in this study. This is because they are attached to residential institutions where the differently-abled children are able to operate from. Each of these schools has a special education teacher assigned by the government to ensure that these children's educational needs are met (Ministry of Education, 2009). There has been a decline in the enrolment of differently-abled children in these schools for the last four years (Sub-county Director of Education Embu East, 2019). Still the reports from the three schools reveal a significant drop on the performance of the differently-abled children compared to the performance of the differently-abled children who were enrolled in these schools many years ago. This calls for an investigation on the amount of educational institutional care offered to the differently-abled children in the area of study and the possible causes of the decline of enrolment and academic performance of the DAC owing to the fact that they only have motor impairments and possess other functional abilities.

The differently-abled children require psychological care just like their able bodied peers (Misauri, 2019). This psychological care is given to them in their families, in the residential institutions or in the educational institutions. Generally the psychological care means any activities used to modify behavior, emotional state, or feelings of the differently-abled children as they cope with the situations of life (Ncube, 2014). They are assisted to develop emotional wellbeing and individual's capacity to live a full and creative life and the flexibility to deal with life's inevitable challenges (Ministry of Labor, 2015). The psychological care also helps the differently-abled children to know and to manage 
themselves, be in touch with their situation and embrace a sense of self-worth, control over behavior, realistic beliefs, spiritual appreciation or belief in purpose, independence, feeling safe and happy, appreciation of others and hope for the future (Ministry of Labor, 2015). This called for a study that would seek to investigate the amount of psychological care offered to the DAC in Runyenjes Constituency since there was a drop in the academic performance of those in schools while some had been withdrawn from the residential institutions. An assessment on psychological care was also required for those at their families since many lived in deplorable conditions.

The care given to the differently-abled children has a great impact on the psychological wellbeing of these children. Many studies have only been done on one environment where this care is offered. Other studies only evaluate the statistical facts about where the DAC are found without going further to probe the type and amount of care in these environments. Still other studies focus more on the people who take care of the DAC finding out the resilience of these care givers and their psychological wellbeing. There has been little concern for the psychological wellbeing of the differently-abled children since much concern has been on the environment they live in, their numbers and the people who take care of them.

The uniqueness of this study was that it went further to investigate the amount of care in all the possible environments where the DAC lived without being limited to the numbers of the DAC, merely identifying the environments or singling only one environment. It focused on the psychological wellbeing of the DAC which had been left out by many studies.

\section{METHODOLOGY}

\section{Research Design}

The study adopted a cross-sectional research design. The aim of cross-sectional studies is to obtain large amounts of data that make possible to generate, robust conclusions, and create new hypotheses that can be investigated with new research as it investigate causal and effect relationships. This makes cross-sectional studies particularly useful for studying a particular phenomenon, whether it is assumed to be the cause or the consequence, or both in a defined population (Zangirolami, Echeimberg\& Leone, 2018).

\section{Target Population of the Study}

The target population of a research is the larger population from which a sample is drawn and to which the researcher intends to generalize his or her findings (Oso, 2016). The target population of this study was 80 differently abled children living in their families and in residential institutions in the area of study (Data from County Social Services Department, Embu County). The study also targeted 5 chaplains who work with the differently-abled children and 5 guidance and counseling teachers working with the differently-abled children. This is because they were considered to be the overseers of the spiritual and psychological care of the DAC in the institutions and in the families in the area of study.

\section{Sample size}

The researcher adopted census method instead of sampling since the target population was small and accessible. A census study, also called complete enumeration is the one that involves the study of every unit, everyone or everything in a population. Oso (2016) further posits that where the subjects under investigation are few and well defined, they can be studied all of them. The sample size therefore comprised of the 80 differently abled children from the three special schools in Embu County. Participants were sampled using simple random sampling.

\section{Research Instruments}

Data were collected using a self-developed Likert scale selfreport questionnaire to assess quality of care given to differently abled children within their homes, institutional residence and educational institutions. Psychological wellbeing was measured using the Ryff's Psychological wellbeing scale.

\section{RESULTS}

Family care and psychological wellbeing of differently-abled children

The study sought to investigate how family care influenced the psychological wellbeing of differently-abled children in Embu County, Kenya. The results are presented in table 1.

Table 1: Influence of family care on psychological wellbeing of differentlyabled children

\begin{tabular}{|c|c|c|}
\hline \multicolumn{2}{|c|}{ Psychological Wellbeing } & Family Care \\
\hline \multirow{3}{*}{ Autonomy } & Pearson Correlation & .201 \\
\hline & Sig. (2-tailed) & .098 \\
\hline & $\mathrm{N}$ & 69 \\
\hline \multirow{3}{*}{$\begin{array}{c}\text { Environmental } \\
\text { Mastery }\end{array}$} & Pearson Correlation & -.054 \\
\hline & Sig. (2-tailed) & .658 \\
\hline & $\mathrm{N}$ & 69 \\
\hline \multirow{3}{*}{ Personal Growth } & Pearson Correlation & $.320^{* *}$ \\
\hline & Sig. (2-tailed) & .007 \\
\hline & $\mathrm{N}$ & 69 \\
\hline \multirow{3}{*}{ Purpose in Life } & Pearson Correlation & -.202 \\
\hline & Sig. (2-tailed) & .099 \\
\hline & $\mathrm{N}$ & 68 \\
\hline \multirow{3}{*}{ Self-Acceptance } & Pearson Correlation & .204 \\
\hline & Sig. (2-tailed) & .093 \\
\hline & $\mathrm{N}$ & 69 \\
\hline \multirow{3}{*}{ Positive Relations } & Pearson Correlation & .203 \\
\hline & Sig. (2-tailed) & .095 \\
\hline & $\mathrm{N}$ & 69 \\
\hline
\end{tabular}


The study indicated that there was a weak positive significant correlation between the family care and personal growth $(\mathrm{r}=$ $0.320, \mathrm{p}<0.05)$. This means that an increase in family care would mean an increase in personal growth. This could be attributed to the affection and concern that the family members have towards the DAC thus boosting the psychological wellbeing of the DAC. The study also indicated a very weak positive insignificant correlation between family care and self-acceptance $(r=0.204, p>0.05)$, positive relations $(\mathrm{r}=0.203, \mathrm{p}>0.05)$ and autonomy $(\mathrm{r}=0.201, \mathrm{p}>0.05)$. The study also indicated that family care had very weak negative insignificant correlation with purpose in life $(r=-0.202$, $p>$ $0.05)$ and environmental mastery $(r=-0.054, p>0.05)$. This means that an increase in family care would decrease purpose in life and environmental mastery. This could be attributed to the fact that excess care to the DAC would lead to overdependence on their family members denying them a chance to do some of the activities on their own.

Residential institutionalized care and psychological wellbeing of differently-abled children This study sought to establish how residential institutional care related to the psychological wellbeing of differently-abled children in Runyenjes Constituency, Embu County, Kenya. The results are presented in the table 2.

Table 2: Relationship between residential institutionalized care and the psychological wellbeing of differently-abled children

\begin{tabular}{|c|c|c|}
\hline \multicolumn{2}{|c|}{ Psychological Wellbeing } & $\begin{array}{c}\text { Residential } \\
\text { Institutional Care }\end{array}$ \\
\hline \multirow{3}{*}{ Autonomy } & $\begin{array}{c}\text { Pearson } \\
\text { Correlation } \\
\end{array}$ & .132 \\
\hline & Sig. (2-tailed) & .279 \\
\hline & $\mathrm{N}$ & 69 \\
\hline \multirow{3}{*}{$\begin{array}{c}\text { Environmental } \\
\text { Mastery }\end{array}$} & $\begin{array}{c}\text { Pearson } \\
\text { Correlation }\end{array}$ & .037 \\
\hline & Sig. (2-tailed) & .763 \\
\hline & $\mathrm{N}$ & 69 \\
\hline \multirow{3}{*}{ Personal Growth } & $\begin{array}{c}\text { Pearson } \\
\text { Correlation }\end{array}$ & $.329^{* *}$ \\
\hline & Sig. (2-tailed) & .006 \\
\hline & $\mathrm{N}$ & 69 \\
\hline \multirow{3}{*}{ Purpose in Life } & $\begin{array}{c}\text { Pearson } \\
\text { Correlation } \\
\end{array}$ & -.074 \\
\hline & Sig. (2-tailed) & .547 \\
\hline & $\mathrm{N}$ & 68 \\
\hline \multirow{3}{*}{ Self-Acceptance } & $\begin{array}{c}\text { Pearson } \\
\text { Correlation }\end{array}$ & .154 \\
\hline & Sig. (2-tailed) & .206 \\
\hline & $\mathrm{N}$ & 69 \\
\hline \multirow{3}{*}{ Positive Relations } & $\begin{array}{c}\text { Pearson } \\
\text { Correlation } \\
\end{array}$ & .044 \\
\hline & Sig. (2-tailed) & .719 \\
\hline & $\mathrm{N}$ & 69 \\
\hline
\end{tabular}

The study indicated that there was a weak positive significant correlation between residential institutionalized care and personal growth $(\mathrm{r}=0.329, \mathrm{p}<0.05)$. This means that an increase in residential institutionalized care would increase personal growth for the DAC. This could be attributed to motivational speeches and guidance and counseling sessions offered to the DAC in the institutions since they are together sharing common challenges. The study also indicated that there was very weak insignificant positive correlation with self-acceptance ( $r=0.154, p>0.05)$, autonomy $(r=0.132$, $p>$ $0.05)$, positive relations $(r=0.044, p>0.05)$ and environmental mastery $(r=0.037, p>0.05)$. The residential institutional care as per the study had very weak negative insignificant correlation with purpose in life $(\mathrm{r}=-0.074, \mathrm{p}>0.05)$. This means that an increase in residential institutionalized would decrease the environmental mastery. This could be attributed to excess care and attention offered to the DAC in the institutions by the care takers and the people who visit them. This would lead the DAC to be over dependent on these people in a way that they are not able to do some things on their own.

\section{Educational care on the psychological wellbeing of differently-abled children}

The study sought to assess the implications of educational care on the psychological wellbeing of the DAC in Runyenjes Constituency. The results are presented in the table 3

Table 3: Relationship between Educational care and psychological wellbeing of differently-abled children

\begin{tabular}{|c|c|c|}
\hline \multicolumn{2}{|c|}{ Psychological Wellbeing } & $\begin{array}{c}\text { Educational } \\
\text { Institution Care }\end{array}$ \\
\hline \multirow{3}{*}{ Autonomy } & $\begin{array}{c}\text { Pearson } \\
\text { Correlation }\end{array}$ & .210 \\
\hline & Sig. (2-tailed) & .083 \\
\hline & $\mathrm{N}$ & 69 \\
\hline \multirow{3}{*}{$\begin{array}{c}\text { Environmental } \\
\text { Mastery }\end{array}$} & $\begin{array}{c}\text { Pearson } \\
\text { Correlation }\end{array}$ & -.110 \\
\hline & Sig. (2-tailed) & .367 \\
\hline & $\mathrm{N}$ & 69 \\
\hline \multirow{3}{*}{ Personal Growth } & $\begin{array}{c}\text { Pearson } \\
\text { Correlation }\end{array}$ & $.449^{* *}$ \\
\hline & Sig. (2-tailed) & .000 \\
\hline & $\mathrm{N}$ & 69 \\
\hline \multirow{3}{*}{ Purpose in Life } & $\begin{array}{c}\text { Pearson } \\
\text { Correlation }\end{array}$ & .073 \\
\hline & Sig. (2-tailed) & .554 \\
\hline & $\mathrm{N}$ & 68 \\
\hline \multirow{3}{*}{ Self-Acceptance } & $\begin{array}{c}\text { Pearson } \\
\text { Correlation }\end{array}$ & -.082 \\
\hline & Sig. (2-tailed) & .502 \\
\hline & $\mathrm{N}$ & 69 \\
\hline \multirow{3}{*}{ Positive Relations } & $\begin{array}{c}\text { Pearson } \\
\text { Correlation }\end{array}$ & -.021 \\
\hline & Sig. (2-tailed) & .862 \\
\hline & $\mathrm{N}$ & 69 \\
\hline
\end{tabular}


The study indicated that there was a moderate positive significant correlation between educational care and personal growth $(\mathrm{r}=0.449, \mathrm{p}<0.05)$. This means that an increase in educational care would increase personal growth of the DAC. This can be attributed to the support by the government in education system and academic elements that boost the personal growth of the DAC. Still the educational care emphasizes greatly on academic achievements where the DAC excel since they have only motor impairments. The study also found a weak positive insignificant correlation between educational care and autonomy $(\mathrm{r}=0.210, \mathrm{p}>0.05)$ and purpose of life $(r=0.073, p>0.05)$. The educational care as per the study had very weak negative insignificant correlation with positive relations $(r=-0.021, p>0.05)$, selfacceptance $(r=-0.082$, p. 0.05$)$ and environmental mastery $(r=$ -0.110, p. 0.05 ). This means that increasing educational care would probably decrease positive relations, self-acceptance and environmental mastery. This could be attributed to the fact that in the educational institutions there are incidents of over emphasis on academic excellence at the expense of other areas of life.

\section{DISCUSSION}

The findings of this study agreed with those of Mulheir (2014) that indicated that the family care was insignificant in promoting autonomy, personal growth and purpose in life. Misauri (2019) too agreed that the family care due to lack of finances and negative mentalities was unable to positively and significantly promote the psychological wellbeing of the DAC. The results of the study on the other hand contradicted the findings of Chernego (2016) that positively and significantly attributed high psychological wellbeing to family care. In the family there was no abuse or exploitation and the family provided child protection, social care, health care and all basic needs. This indicated a strong correlation between family care and psychological wellbeing.

Other studies also revealed that having a child with disability impacted the whole family, generating specific challenges related to caring, income generation and the psychosocial health of the care takers especially the women (Adeniyi \& Omigbodun, 2016). The stigma and shame associated with having a disabled child was pervasive and influenced how children were cared for (Zuurmond et al, 2016). It also affected the wider support like provision of assistive devices as well as the difficult terrain for a wheelchair, toileting and the personal care of children, and limited access to water. The children with disabilities were more likely to be malnourished than their able bodied peers and even their siblings (Kuper, 2015).

The findings were consistent with those from other studies done previously in that the residential institutionalized care had weak positive insignificant correlation with the majority of the elements of psychological wellbeing. Browne (2015) found that the residential institutions affected the social, emotional, intellectual and behavioral development for the DAC and thus put their psychological wellbeing at stake due to the exposure to neglect, exploitation, abuse and lack of individual care. Another study in western and central European countries of the European Union (EU) by Browne (2015) concluded that institutions negatively affected the child's social behavior and interaction with others, as well as negatively affecting the formation of emotional attachments. Additionally, institutionalization was linked to poor cognitive performance and language deficits (Browne, 2015). Institutionalization of children was also found to have led to developmental delays due to the absence of physical stimulation and presence of daily neglect, motor skill delay, inadequate brain development, impairment in social and cognitive skills, and speech impediments (Browne, 2015). Attachment disorders were also found leading to harmful selfinflicting actions, anxiety disorders, eating disorders, as well as difficulty in forming healthy relationships

Other studies done previously showed that educational care may not significantly influence many elements of the psychological wellbeing of the DAC (Dreyer, 2017). Adeniyi \& Omigbodun (2016) affirmed that the educational institutions lacked structural support; adequate facilities and those available were irrelevant for the promotion of the psychological wellbeing of the DAC. In the current study it was noted that all other domains of the psychological wellbeing except personal growth were not influenced by the quality of care.

\section{RECOMMENDATIONS}

The study found missing elements that were a challenge to offering psychological care and eventually not promoting the psychological wellbeing of the DAC and therefore made recommendations to five stakeholders who would be vital in the implementation of the findings of this study. These were the parents or the guardians of the DAC, the government, the church, the managers of the institutions and the general community.

To the parents or the guardians of the DAC and the community this study recommended frequent interactions and exposure of the DAC to many people while understanding them in their situation. This would create positive relations, help them accept themselves and above all realize that they have very much other potential in their lives. The research recommended the involvement of the community, wellwishers and charitable groups and to promote the psychological wellbeing of the DAC.

To the government this research recommended allocation of resources like funds and other required facilities in the institutions where the DAC live. The research recommended training of the persons handling the DAC like the teachers and counselors who would assist greatly in the promotion of the psychological wellbeing of the DAC. The government would also assign to specific teachers the duties of handling the DAC. 
To the managers of the institutions the research recommended allocation of enough time in the programs for the DAC to interact with chaplains, counsellors and motivational speakers. To the church the research recommended assigning chaplaincy services, pastoral care and spiritual nourishment to a specific chaplain who would plan and come up with a way of promoting the psychological wellbeing of the DAC. This would ensure the availability of the chaplains to the DAC thus playing a key role in the promotion of their psychological wellbeing.

\section{REFERENCES}

[1] Adeniyi, Y. C. \&Omigbodun, O. O. (2016) 'Effect of a classroombased intervention on the social skills of pupils with intellectual disability in Southwest Nigeria', Journal of Child and Adolescent Psychiatry and Mental Health, 10(1),1-29.

[2] Arieh, Asher \& Ivaar, (2014). Multifaceted Concept of Child Wellbeing. Journal of Handbook of child wellbeing, (1), 1-27.

[3] Badu E (2016). Experiences of parents of children with intellectual disabilities in the Ashanti Region of Ghana. Journal of Social Inclusion; downloaded on https://josi.journals.griffith.edu.au/index.php/inclusion/article/vie w/796/757.

[4] Bayat, M. (2017) Evidence of resilience in families of children with autism. Journal of Intellectual Disability Research, 51, 702714.

[5] Browne Kevin. (2015). The Risk of Harm to Young Children in Institutional Care. Retrieved from http://www.crin.org/docs/The_Risk_of_Harm.pdf

[6] Chernego, D. I. \& Muhamedrahimov, R. J. (2016).Comparative Study on Mental Development of Preterm and Full term Infants in age 3 to 24 months Raised in an Orphanage. Psychological journal, 35(4), 47-55

[7] Dreyer Lorna. (2017). Inclusive Education. Journal on Education Studies for Initial Teacher Development, 1, 383-403.

[8] Government of Kenya (2001) The Children's Act 2001.Government Printer. Nairobi.

[9] Grant, G., Ramcharan, P. and Flynn, M. (2007) Resilience in families with children and adult members with intellectual disabilities: Tracing elements of a psycho-social model. Journal of Applied Research in Intellectual, 20 (6), 563-575.

[10] Kenya National Commission On Human Rights Occasional Report (2007). Objects Of Pity Or Individuals With Rights: The Right To Education For Children With Special Needs. Nairobi: Government Printer.

[11] Kett M. \& Van Ommeren M., (2009), 'Disability, conflict, and emergencies', The Lancet 374, 1801-1803. http://dx.doi.org/10.1016/S0140-6736(09)62024-9]

[12] Kuper, H., Saran, A. \& White, H. (2015)Rapid Evidence Assessment (REA) of What Works to Improve Educational
Outcomes for People with Disabilities in Low- and Middle-Income Countries. International Centre for Evidence in Disability, London School of Hygiene CampbellCollaborationhttps://assets.publishing.service.gov.uk/gov ernment/uploads/system/uploads/attachment_data/file/727787/Edu cation_Rapid_Review_full_report.pdf Malinda H. N. (2005). Integrating the Physically Disabled Children into Regular Schools in Kenya.An Analysis of Causes of Marginalization, the Life Situation of the Disabled Children and Proposals for enhancing their Inclusion and Welfare.A Case Study of Machakos District. University of Osnabrück-Germany.Unpublished Project.

[13] Ministry of Education (2009).The National Special Needs Education Framework (2009). Government Printer. Nairobi.

[14] Ministry of Gender and social services, Embu west sub-county, (2019).

[15] MisauriThembo , (2019). “ Children with Disabilities Still neglected in homes". Daily Monitor, Kampala Uganda.

[16] Mulheir, G. (2012). Deinstitutionalisation-A Human Rights Priority for Children with Disabilities. The Equal Rights Review,9,117-137.Retrievedfrom http://www.equalrightstrust.org/ertdocumentbank/err9_mulheir.pd f

[17] Ncube, A. C. (2014). Social and Psychological Effects of Inclusive Classrooms: Insights from Teachers of Inclusive Classes in Selected Primary Schools in Zimbabwe. Journal of Emerging Trends in Educational Research and Policy Studies (JETERAPS),5(4), 449- 556. https://pdfs.semanticscholar.org/5a0f/cefbf477ce1c2195ffb05fc3c b82f9172916.pdf

[18] Orr B. Kenn (2015) The views and experiences of young people in Northern Ireland: Exploring participation, knowledge and respect for rights, community life and leisure, and mental health, Children's Law Centre and Save the Children.

[19] Oso, Yuko Willis (2016). Social Science Research: Principles and Practice. Jomo Kenyatta Foundation, English Press Ltd, Nairobi, Kenya

[20] Ryff, C. D. (2017). Well-being with soul: Science in pursuit of human potential. Perspectives on Psychological Science, 13(2), 242-248. doi:10.1177/1745691617699836

[21] United Nations Children's Fund (UNICEF) (2013).Children on the brink: A joint report of new orphan estimates and a framework for action $\left(4^{\text {th }}\right.$. ed $)$ Switzerland/New York/Washington,http://data.unaids.org/Publications/External

[22] Zangirolami-Raimundo J, Echeimberg J. O, Leone C. (2018). Research Methodology Topics: Cross-sectional Studies. Journal of Human Growth and Development.28(3):356-360. DOI: http://dx.doi.org/10.7322/jhgd.152198

[23] Zuurmond, M., Nyapera, V., Mwenda, V., Kisia, J., Rono, H. \& Palmer, J., (2016), 'Childhood disability in Turkana, Kenya: Understanding how caregivers carers cope in a complex humanitarian setting', African Journal of Disability. 